\title{
OS INSTITUTOS FEDERAIS EM TRÊS DIMENSÕES DE ANÁLISE
}

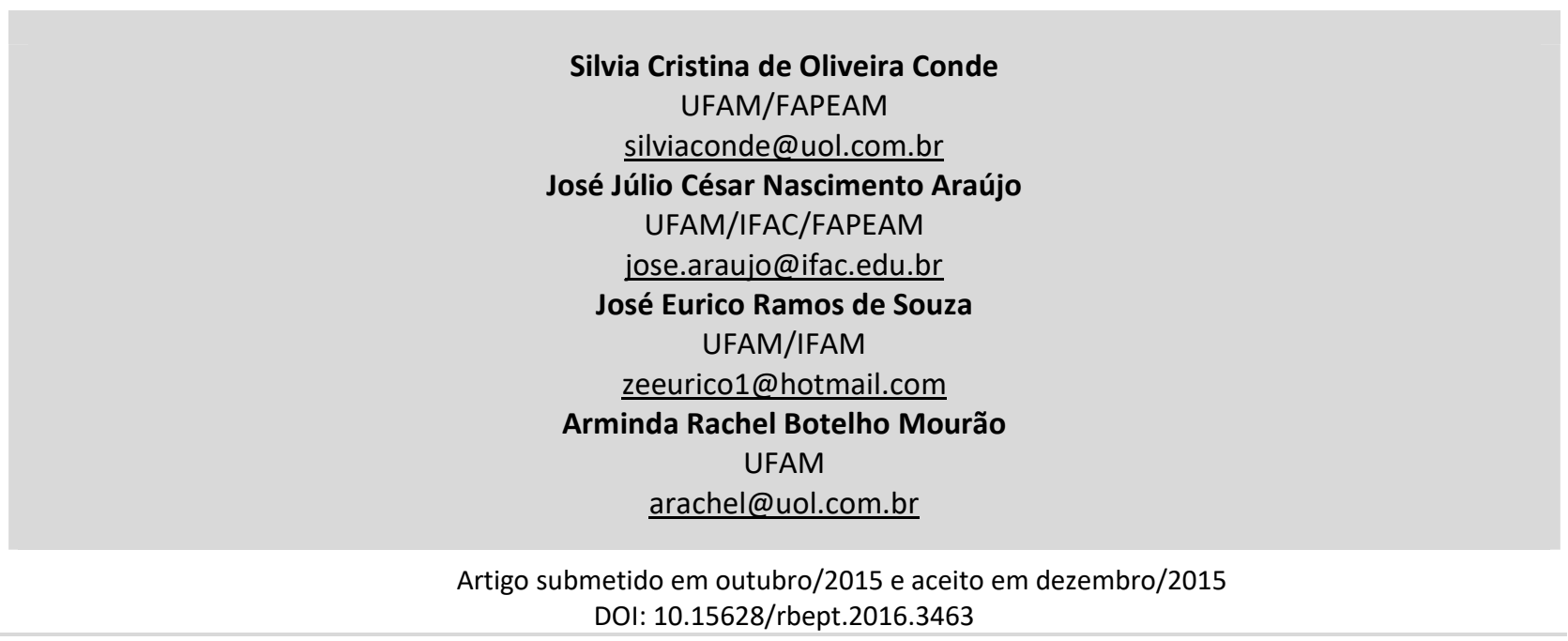

\section{RESUMO}

Discute as finalidades dos Institutos Federais (IFs) na tentativa de recuperar os movimentos da ação política envolvida em sua constituição. Por meio da análise documental e da revisão bibliográfica apresenta como a legislação vai apontando contradições entre o pensado e o realizado, sintetizando que a política é sempre uma arena de disputa de projetos societários. Por fim, debate, a partir das dimensões política social, agência de pesquisa e desenvolvimento e lócus de formação de professores, como os IFs reagem às exigências políticas, econômicas e sociais para responder as finalidades de sua institucionalidade na Amazônia.

PALAVRAS-CHAVE: Institutos Federais, política social, formação de professores, agência de desenvolvimento.

\section{THE FEDERALS INSTITUTES IN THREE DIMENSIONS OF ANALYSIS}

\begin{abstract}
Discusses the purposes of the Federal Institutes (FIs) in an attempt to regain the political action of the movements involved in its constitution. By document analysis and literature review shows how legislation will pointing contradictions between thought and done, summarizing that politics is always a dispute arena of
\end{abstract}

corporate projects. Finally, debate, from the social political, research and development agency and locus of teacher training, as Fls react to political, economic and social requirements to meet the objectives of their institutions in the Amazon.

KEYWORDS: Federal institutes, social policy, teacher training, development agency. 


\title{
10 HORIZONTE DA DISCUSSÃO
}

A orientação analítica e metodológica, dos autores, é o materialismo histórico dialético. Pois, se compreende que a política educacional se constrói nas constantes co-relações de forças de grupos, classes sociais e interesses. Sendo necessário compreender a materialidade da realidade para apreender o todo.

Dito isso, é fato que a reorganização produtiva do capital em escala global tem provocado reformas em todos os âmbitos das relações sociais capitalistas. As reformas no campo da educação, sob tal contexto, são objeto de análise deste trabalho. Deitos (2010) tem apontado que a política educacional é constituinte da política social. Para o autor:

\begin{abstract}
As políticas públicas diretamente definidas e dirigidas pelo Estado são compreendidas como o resultado de mediações teórico ideológicas e socioeconômicas e estão diretamente imbricadas no processo de produção social da riqueza e, consequentemente, de sua repartição e distribuição. A política educacional, particularmente a empreendida no Brasil a partir a década de 1990, é a articulação e a consumação de forças econômicas e políticas hegemônicas que sustentam proposições que revelam forte tendência predominante de cunho liberal ou social-liberal e definem significativamente os rumos das políticas públicas e da educação nacional. (DEITOS, 2010, p. 209)
\end{abstract}

Por isso, há também, similaridades ideológicas entre os empresários de ensino e os industriais, materializando-se de forma conflituosa nas políticas públicas em educação, fundadas na determinação tanto do capital mercantil educacional como capital industrial de transformar a educação em mercadoria e/ou serviço (RODRIGUES, 2007). Esta é a lógica para a atuação do capital no campo educacional.

No Brasil, há diversos movimentos que caminham para a mercantilização da educação. Em um eixo que caminha do global para o local encontramos as forças sociometabólicas do capital agindo para encontrar espaço de exploração dos negócios educacionais em escala planetária. No eixo que vai do central para o local encontramos estratégias para "adaptar" sistemas educacionais às novas demandas do capital. No eixo que vai do público para o privado nos deparamos com a estratégia clara de aumento de produtividade dos sistemas e eficácia nos gastos com educação (o público não estatal e as estratégias de racionalização do público pela lógica do privado). E na linha que vai do privado para o público encontramos a possibilidade de mistura dos dois eixos através dos mecanismos legais como a Lei de Inovação, a parceria público-privada, programas educacionais de acesso à universidade e financiamento estudantil e isenção fiscal para instituições privadas. Denunciando uma "substituição aos modelos central/público, relevante nos governos populistas e central/privado, característico dos regimes autoritário/ burocrático" (FLEURY, 1994, p. 233).

Isso ocorre porque, segundo Rodrigues (2007, p. 86), “o capital busca, através da transformação da educação em mercadoria, a mediação para a manutenção do seu interesse mais geral - a valorização do valor através da exploração do trabalho vivo". Os principais articuladores 
desta lógica sobre os sistemas de educação são as agências multilaterais como o Banco Mundial ${ }^{1}$ e a Organização Mundial do Comércio. A principal proposição destes organismos para a política educativa nos países em desenvolvimento é a ampliação do acesso à educação sem aumento do gasto público. Neste sentido, dois mecanismos têm sido usados pelos Estados: primeiro, a expansão da atuação dos sistemas privados de educação através do financiamento, da diversificação e flexibilização e, por outro lado, a redistribuição interna do gasto público com educação de setores sociais mais carentes (HADDAD, 2008).

Bonal (2009) analisando o papel da globalização econômica e das agências multilaterais sobre as políticas educacionais assevera que um dos aspectos mais significativos da produção do discurso hegemônico das políticas educativas é a evocação dos benefícios universais das reformas educacionais. Embora seja a globalização e o capital que exija tais reformas, estas devem ser entendidas como benéfica para todos. Mas, no limite da análise, estas reformas revelem efeitos nocivos aos grupos menos favorecidos.

Boron (2006) assevera que dentre as diversas modificações do sistema de ensino na América Latina, pode-se destacar a massificação do ensino superior (expansão sem precedentes de matriculas), mercantilização dos serviços educacionais, ressignificação do público e do privado e declínio da qualidade. Tais mudanças cumprem as recomendações estabelecidas pelo Consenso de Washington e pelo Banco Mundial compreendendo educação como parte do mercado e não como direito público como se advoga.

O caminho brasileiro da reforma do ensino superior e da educação profissional e tecnológica tem se dado em duas direções. Pela via do setor privado possibilitando a diferenciação institucional e o financiamento público das instituições privadas, através de programas de acesso para estratos menos favorecidos (PROUNI, PRONATEC e FIES) ${ }^{2}$. Por outro lado, amplia o acesso a vagas em Instituições de Ensino Superior (IES) públicas por meio do REUNI ${ }^{3}$ e pela recente diversificação das finalidades dos Institutos Federais (IFs).

Esta nova institucionalidade emerge a partir de uma proposta governamental que vai se delineando a partir de diversos documentos oficiais elaborados entre os anos de 2007 e 2008. Com estes documentos o governo federal aborta as discussões sobre as universidades tecnológicas e assume um projeto para a Educação Profissional e Tecnológica. Alguns elementos deste projeto serão abordados na próxima subseção.

\footnotetext{
${ }^{1}$ Ver TOMMASI, Lívia de; WARDE, Mirian Jorge; HADDAD, Sérgio. O Banco Mundial e as Políticas Educacionais. 4 ed. São Paulo: Cortez, 2003.

${ }^{2}$ Programa Universidade para Todos que concede bolsas de estudo integrais e parciais de $50 \%$ em instituições privadas de educação superior, em cursos de graduação e sequenciais de formação específica, a estudantes brasileiros sem diploma de nível superior (http://siteprouni.mec.gov.br/). O Programa Nacional de Acesso ao Ensino Técnico e Emprego que expande, interioriza e democratiza a oferta de cursos de educação profissional e tecnológica no país (http://pronatec.mec.gov.br/institucional-90037/o-que-e-o-pronatec). O Fundo de Financiamento Estudantil financia a graduação na educação superior de estudantes matriculados em instituições privadas (http://sisfiesportal.mec.gov.br/fies.html).

3 Programa de Apoio a Planos de Reestruturação e Expansão das Universidades Federais que tem como principal objetivo ampliar o acesso e a permanência na educação superior.
} 


\section{O PROJETO DE/DO GOVERNO}

Quatro documentos são reveladores para a configuração dos Institutos como projeto institucional para a Educação Profissional e Tecnológica: o decreto n. 6.095 (BRASIL, 2007a), a chamada pública MEC/SETEC n. 01 (BRASIL, 2007b), a chamada pública MEC/SETEC n. 2 (BRASIL, 2007c) e a lei. 11.892 (BRASIL, 2008).

O Decreto 6.095 (BRASIL, 2007a) evidenciou as primeiras diretrizes e fundamentos e anuncia o processo de reorganização das instituições federais de educação profissional e tecnológica pautado pelo modelo Instituto Federal de Educação, Ciência e Tecnologia - IFET ${ }^{4}$. Os IFETs seriam: instituições de educação superior, básica e profissional, pluricurricular e multicampi; autarquias com autonomia administrativa, patrimonial, didático-pedagógica e disciplinar; formados a partir da integração de instituições federais de educação profissional e tecnológica 5 .

Otranto (2010), ao abordar criticamente o processo de criação e implantação dos Institutos, analisa as reações ao Decreto 6.095 (BRASIL, 2007a) nas Escolas Agrotécnicas Federais (EAFs), nos Centros Federais de Educação Tecnológica (CEFETs) e nas Escolas Técnicas vinculadas às Universidades Federais. Em síntese, conforme a autora, todas as EAFs se tornaram um dos campi dos Institutos assombradas pela possibilidade de abandono governamental no caso de não adesão.

Os CEFETs do Rio de Janeiro e de Minas Gerais não aderiram à proposta sob os argumentos de retrocesso acadêmico e a presunção de limitação de financiamento imposta pela destinação de $50 \%$ das vagas para ensino médio-profissional e $20 \%$ para o Programa Nacional de Integração da Educação Profissional à Educação Básica na Modalidade de Educação de Jovens e Adultos - PROEJA. A adesão dos outros CEFETs ${ }^{6}$ justificou-se pelo aumento dos cargos comissionados e pela potencialidade destes se tornarem sede das reitorias (OTRANTO, 2010).

Quanto as Escolas Técnicas vinculadas às Universidades Federais, a autora afirma que vinte quatro, das trinta e duas instituições, não aderiram à proposta governamental devido à confiança nas universidades a que se vinculavam e por medo de os cursos atenderem aos interesses privados locais. Otranto (2010) chega a algumas conclusões, entre elas: os IFETs são peças-chave da reengenharia da Rede Federal de Educação Profissional, Científica e Tecnológica (RFEPCT), o modelo IFET além de nortear a RFEPCT também vai definir a expansão e essas instituições são a expressão maior da atual política pública de educação profissional brasileira.

Estas conclusões se sustentam no Art. 13 do decreto 6.095 (BRASIL, 2007a), na Chamada Pública n. 2 (BRASIL, 2007c) e na Lei 11.892 (BRASIL, 2008). No primeiro documento fica clara a primazia do modelo IFET para a criação e a expansão de instituições federais de educação profissional e tecnológica. O segundo documento ressalta a implantação dos IFETs como uma ação

\footnotetext{
${ }^{4}$ Neste decreto surge a sigla IFET referente a Institutos Federais de Ciência e Tecnologia. Neste trabalho usa-se o termo IFET para a análise documental acompanhando o movimento histórico para mostrar que a partir da Lei 11.892 (BRASIL, 2008) abandona-se a sigla IFET e se adota Institutos Federais (IFs).

5 Através da agregação voluntária dos Centros Federais de Educação Tecnológica, Escolas Técnicas Federais, Escolas Agrotécnicas Federais e Escolas Técnicas vinculadas às Universidades Federais.

${ }^{6}$ A análise de Brandão (2010) contextualiza que os CEFETs discutiam o processo de transformação em Universidades Tecnológicas quando foi apresentada a proposta de IFETs. A autora enfatiza que as Universidades Tecnológicas e os IFETs são políticas distintas para Educação Profissional, a primeira tem como foco os cursos superiores de tecnologia e a segunda o foco é a educação profissional de nível médio.
} 
de relevo do Plano de Desenvolvimento da Educação e o último documento condiciona a criação e expansão de outras instituições ao modelo Instituto Federal.

No entanto, vale destacar um movimento, aparentemente, contraditório: no mesmo dia da publicação do decreto 6.095/2007, que lança o IFET como o novo modelo institucional para a educação profissional e tecnológica, é lançada a Chamada Pública n. 1 MEC/SETEC (BRASIL, 2007b) ${ }^{7}$. Este documento não faz referência ao modelo IFET, o foco é a implantação de "uma escola técnica em cada cidade pólo do país"8. Inferimos que o processo de expansão da Rede Federal de Educação Tecnológica ${ }^{9}$ ocorreria independentemente da adesão das instituições à proposta governamental de ifetização ${ }^{10}$.

Esta inferência invalida-se com a Chamada Pública MEC/SETEC n. 2 (BRASIL, 2007c) que é lançada sete meses depois da publicação dos dois documentos acima referidos. O objeto desta chamada é o acolhimento de propostas para a implantação dos IFETs que poderão ser constituídos pela transformação ou integração instituições federais de educação profissional e tecnológica. Ou seja, haveria a intersecção do processo de expansão e a implantação do modelo IFET.

Neste documento, o primeiro, dos diversos objetivos que definem a missão institucional dos IFETs, é: "ofertar educação profissional e tecnológica, como processo educativo e investigativo, em todos os seus níveis e modalidades, sobretudo de nível médio, reafirmando a verticalização como um dos princípios do IFET" (BRASIL, 2007c. Grifo nosso).

A ênfase no nível médio é feita por meio de uma redação ambígua, apesar da apresentação de um novo componente: a verticalização. Com a aprovação da Lei 11.892 (BRASIL, 2008) a ênfase deixa de ser por meio de redação ambígua e passa a ser por meio de definição de percentuais de vagas: cabe aos IFs ofertar $50 \%$ de suas vagas para o ensino médio ${ }^{11}$ e $20 \%$ para as licenciaturas.

Em cada um dos documentos aqui referidos é possível perceber a configuração institucional delineada pelo governo federal entre 2007 e 2008. Na Lei 11.9892 (BRASIL, 2008), que instituiu oficialmente a Rede Federal de Educação Profissional Científica e Tecnológica e criou os IFs, se consolidou os seguintes aspectos contemplados nos documentos anteriores:

a. a agregação de Centros Federais de Educação Tecnológica - CEFETs (com exceção de Minas Gerais e Rio de Janeiro), Escolas Técnicas Federais - ETFs, Escolas Agrotécnicas Federais - EAFs e Escolas Técnicas vinculadas às Universidades Federais ${ }^{12}$;

b. os IFs como instituições de educação superior, básica e profissional, pluricurriculares e multicampi;

c. a equiparação dos IFs às universidades federais;

\footnotetext{
${ }^{7}$ Ação de apoio ao Plano de Expansão da Rede Federal de Educação Tecnológica - Fase II.

${ }^{8}$ Tema da segunda fase de expansão expresso em documentos disponíveis na internet com a logomarca do Ministério da Educação.

${ }^{9}$ Terminologia da Rede que consta no documento em questão.

${ }^{10}$ Aqui considerado o processo de transformação das instituições de educação profissional e tecnológica em IFETs. A Lei 11.892 (BRASIL, 2008) encerra esta dúvida ao condicionar, em seu Art. 15, a criação e a expansão de instituições federais de educação profissional e tecnológica ao modelo Instituto Federal.

${ }^{11}$ Para os concluintes do Ensino Fundamental e para os estudantes da modalidade Educação de Jovens e Adultos.

${ }^{12}$ Apenas oito Escolas Técnicas Vinculadas às Universidades Federais foram integradas aos IFs. Vinte quatro permaneceram vinculadas às Universidades Federais (BRASIL, 2008).
} 
d. a oferta de educação profissional e tecnológica, em todos os níveis e modalidades;

e. o desenvolvimento da educação profissional e tecnológica para a geração e a adaptação de soluções técnicas e tecnológicas às demandas sociais e peculiaridades regionais;

f. a consolidação e fortalecimento dos arranjos produtivos locais;

g. centro de excelência na oferta do ensino de ciências;

h. a capacitação técnica e atualização pedagógica aos docentes das redes públicas de ensino; programas de extensão e de divulgação científica e tecnológica;

i. a pesquisa aplicada, a produção cultural, o empreendedorismo, o cooperativismo e o desenvolvimento científico e tecnológico.

A novidade que surge na lei é o compromisso dos IFs com a produção, o desenvolvimento e a transferência de tecnologias sociais e como espaço de formação de professores. Em síntese, da institucionalidade criada pelo governo federal emergem três dimensões para os Institutos Federais: política social, agências de desenvolvimento local e lócus de formação de professores. Estas dimensões serão abordadas na próxima subseção.

\section{OLHANDO POR DENTRO}

Os IFs se constituem em espaços de uma disputa, pois podem atender aos circuitos do Capital ou, por outro lado, construir uma "hegemonia às avessas" (OLIVEIRA, 2010). Como política social compensatória os IFs descentralizam e interiorizam o ensino técnico de nível médio e educação superior e são catalisadores de outras políticas sociais. Como política social entende-se aquela que "objetiva permitir aos indivíduos a satisfação de certas necessidades não levadas em conta pelo mercado capitalista" (VIEIRA, 1992, p. 29).

Nesta dimensão os IFs se consolidam como uma inegável resposta contestatória ao capital investido de benefício social. Como se observa no gráfico abaixo:

Brasil - Evolução das matrículas na Rede Federal de Educação

Profissional e Tecnológica (em milhares) 2003- 2012

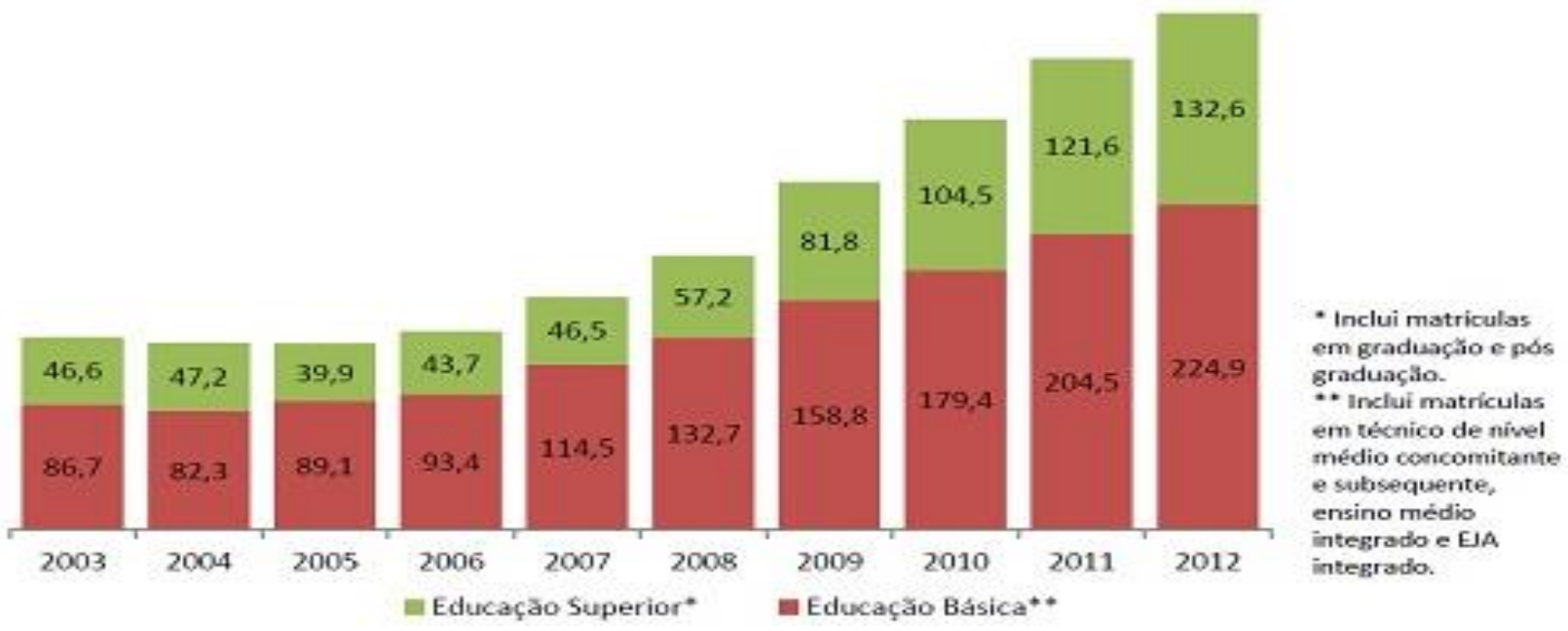

Fonte: MEC/Relatório Educação para todos no Brasil 2000-2015 (2014, p.38). 
A análise do gráfico permite inferir que houve um aumento exponencial de matrículas de ensino médio técnico e superior no período que compreende as três fases de expansão e consolidação da Rede de EPT no Brasil ${ }^{13}$. A implantação dos IFs em 2008 provocou um aumento de aproximadamente $172 \%$ das vagas do ensino técnico e $235 \%$ das vagas do ensino superior em relação aos dados de 2012.

Esta é uma dimensão importante e faz parte de uma política agressiva de massificação do ensino superior e técnico para as regiões afastadas dos grandes centros metropolitanos. 0 pretexto de fazer tal expansão a partir da Rede de EPT nasce do consenso que estas unidades federais de ensino, distribuídas em todos os estados da federação, são os expoentes da "qualidade do ensino", principalmente no nível médio. Essa política social compensatória é articulada sob o simulacro da fetichização da qualidade ${ }^{14}$, das escolas técnicas, como se este modelo sozinho fosse capaz de responder as demandas por ensino médio articulado com profissionalização ao mesmo tempo como modelo capaz de interiorizar o ensino superior em regiões remotas do país.

Não obstante, como política social os IFs assumem o papel de articulador das ações educativas compensatórias do governo. Nesta dimensão os IFs passam a atuar como unidades de formação de jovens e adultos (BRASIL, 2006). Além disso, responsabilizam-se pelos programas Programa Mulheres Mil (MINISTÉRIO DA EDUCAÇÃO, 2011) e o Programa Nacional de Acesso ao Ensino Técnico e Emprego - PRONATEC (BRASIL, 2011), e ainda é braço extensivo da ação formativa de vários ministérios como o de Pesca, o do Desenvolvimento Agrário e do Trabalho ${ }^{15}$.

Na construção da institucionalidade dos IFs há elementos que demonstram também a ação em outro eixo: agência de desenvolvimento local. Como mencionamos acima, na ação das políticas educacionais se observa ações que vem do global para o local, mas também há na política dos IFs uma articulação do local para o global como campos de contestação.

Em outras palavras, ao atrelar a oferta dos cursos dos IFs a uma base tecnológica e aos arranjos produtivos locais cria-se a possibilidade de construção de respostas ao Capital diferenciadas em cada contexto, mesmo que todas elas ainda esbarrem nos ciclos metabólicos do capitalismo.

Conforme Art. 6 (BRASIL, 2008), a oferta de curso técnicos integrados e subseqüentes precisa incorporar a identificação dos ingredientes tecnológicos - base tecnológica - os acondicionamentos lógicos constituídos por estas bases - matriz tecnológica - a co-relação da matriz central que perpassa esta base e esta matriz - eixo tecnológico - e por fim organizar na natureza e na identidade deste curso os arranjos produtivos e sociais locais (APLs). Pautado na intencionalidade de produzir desenvolvimento na região e permitindo a verticalidade do ingresso

\footnotetext{
${ }^{13}$ A expansão da Rede Federal de Educação Tecnológica ocorreu em três fases. A Fase I (2005-2007), a Fase II (20082010) e a Fase III (que iniciou em 2011). O movimento de expansão é diferente do movimento de criação dos IFs, mas ambos se tornam congruentes conforme foi demonstrado na subseção anterior.

14 Por exemplo, uma entre tantas matérias de jornais da época, a Folha de São Paulo de 09/02/2006, na reportagem intitulada SP tem 14 escolas top no ranking do Enem, assinada por Christianne González, ressalta o desempenho e a qualidade dos CEFETs nas avaliações do MEC. Disponível em http://www1.folha.uol.com.br/folha/educacao/ult305u 18352.shtml. Acesso em: 20 mai. 2015.

15 Ler PCPR Evolução das Metas - Pesca e Aquicultura -Exercício 2014, p.03, publicado em 30.03 .2015 www.mpa.gov.br/files/docs/Programas_e.../Objetivo\%20-\%200576.rtf. Acesso em: 20 mai. 2015.
} 
na educação básica ao ensino superior. Talvez, esta mudança ainda não seja percebida em sua totalidade na maioria dos IFs.

Algumas questões nos inquietam. Qual autonomia possui os IFs para interferir diretamente no processo de desenvolvimento local? Como os IFs em um sistema fortemente regulado e centralmente controlado, como o Ministério da Educação, organizarão e executarão ações que levem ao desenvolvimento local? Uma Instituição educacional é capaz de articular esta demanda estatal?

Na dimensão da formação de professores, os IFs devem ofertar $20 \%$ de suas vagas para as licenciaturas. Este processo é permeado por contradições, uma vez que a obrigatoriedade da oferta levou muitos institutos a trabalhar a formação de professores sem que houvesse condições físicas, estruturais, pedagógicas para isso. O estudo de Lima (2012):

(...) permite inferir que a formação de professores nos IFs é um fenômeno permeado por contradições. Pois, aponta para a expansão de uma formação pública e gratuita, trazendo o Estado como promotor da oferta educacional, embora se aproxime de uma concepção pragmática da formação de professores, com o incentivo de uma pesquisa aplicada, voltada para os problemas do cotidiano da prática profissional (LIMA, 2012, p.09).

Esta dimensão é transferida para os IFs sob o pretexto da necessidade de formação de professores para as áreas de ciências (matemática, biologia, química e física) para a educação básica. Mas, a verticalidade provoca a intensificação do trabalho docente, pela multiplicidade de modalidades com as quais o professor deve trabalhar. Obrigando o professor a polivalência, a versatilidade e a flexibilidade. A verticalização permite visualizar o tensionamento e o entrelaçamento existente entre ensino e sociedade, governo e capital.

\section{APONTAMENTOS FINAIS}

Qual o sentido desta 'invenção de instituição'? É esta instituição um modelo original para enfrentar a falência do ensino médio ou apenas segue a cartilha das agências multilaterais, sob o simulacro da 'nova institucionalidade'?

As dimensões apontadas se articulam com as múltiplas causalidades deste projeto de governo, que se configurou como política pública. É fundamental não se abster do entendimento deste projeto a partir de suas relações com a política econômica, da concepção de estado que o embasa e do processo da luta de classes, aspectos não discutidos em seus detalhes dado os limites deste trabalho.

A materialização desta proposta dos IFs, contudo, exige um investimento constante na formação dos quadros docentes, na carreira, nas condições de permanência dos alunos, no incentivo a pesquisa, na tessitura mais acurada entre oferta e as demandas do território, na ampliação da oferta e numa articulação mais profunda que garanta um real ensino médio integrado.

Sem isso, o projeto tende a naufragar e viver sob a 'emergência da próxima reforma'. Os institutos não podem se consolidar apenas como uma política focalizada de ensino médio técnico (integrado e subsequente). Mas, como modelo de instituição capaz de produzir massa crítica que 
leve a novos padrões de trabalho, de sociedade e de educação, que oportunizem a emancipação política e humana.

Aqui vale à pena relembrar as recomendações de István Mészáros (2007):

Portanto o papel da educação é supremo tanto para a elaboração de estratégias apropriadas, adequadas a mudar as condições objetivas de reprodução, como para a auto-mudança consciente dos indivíduos chamados a concretizar a criação de uma ordem social metabólica radicalmente diferente. [...]. A este respeito dois conceitos chave devem ser mantidos sob a nossa atenção: a universalização da educação e a universalização do trabalho como uma atividade humana autosatisfatória. De fato nem uma das duas é viável sem a outra. (MÉSZAROS, 2007 p. 125 , grifo nosso).

A expansão das instituições federais de ensino técnico e tecnológico pela aproximação Instituição-Sociedade, orientada para o empreendedorismo e para formação em massa do sujeito trabalhador especializado, fundamenta-se nos marcos que procuram transformar as IES em "agências" de desenvolvimento e solução de problemas locais calcadas na Teoria do Capital Humano. Vale ressaltar que a universalização do trabalho não nasce da especialização do trabalhador. O que a ideologia da empregabilidade sustenta é a responsabilização dos trabalhadores pelo desemprego, exigindo-Ihes requalificação constante. Por isso, só tem sentido universalização da qualificação do trabalhador se for acompanhada da universalização do trabalho.

Na Amazônia ocidental, lócus de nossos processos de investigação e de atuação profissional, os IFs podem articular estas dimensões que compõem sua institucionalidade com os desafios amazônicos se conseguirem avançar democraticamente no acesso e permanência de trabalhadores em cursos comprometidos com a emancipação política, econômica, sociocultural do homem amazônida, superando a lógica do mercado.

\section{REFERÊNCIAS}

1. BONAL, X. The World Bank Global Education Policy and the Post-Washington Consensus. International Studies in Sociology of Educational 12 (1): 3-21, 2002. Disponível em: <http://dx.doi.org/10.1080/09620210200200080>. Acesso em: 20 mai. 2015.

2. BORON, Atílio. Reforming the Reforms: Transformation and Crisis in Latin American and Caribbean Universities. In: RHOADS, Robert A.; TORRES, Carlos Alberto. The university, state, and market : the political economy of globalization in the Americas. California- USA: Stanford University Press, 2006.

3. BRANDÃO, Marisa. O governo Lula e a chamada Educação Profissional e Tecnológica. In: Retta, vol. 1, n. 1, p.61-87, jan.-jun., 2010. Disponível em: http://www.ufrrj.br/SEER/index.php?journal=retta\&page=article\&op=view\&path\%5B\%5D=4 94\&path\%5B\%5D=242. Acesso em: 18 de set. 2014.

4. BRASIL. Decreto $\mathbf{n}^{\circ}$ 6.095, de 24 de abril de 2007. Disponível em: <http://www.planalto.gov.br/ccivil_03/_ato2007-2010/2007/decreto/d6095.htm>. Acesso em: 3 mar. 2014.

5. Chamada Pública MEC/SETEC n. 001/2007. Chamada pública de propostas para apoio ao Plano de Expansão da Rede Federal de Educação Tecnológica - Fase II. Disponível em: 
<http://portal.mec.gov.br/arquivos/pdf/edital_chamadapublica.pdf $>$. Acesso em: 1 mai. 2015.

6. Chamada Pública MEC/SETEC n.o 002/2007. Chamada Pública de Propostas para constituição dos Institutos Federais De Educação, Ciência e Tecnologia - IFET. Disponível em:< http://portal.mec.gov.br/arquivos/pdf/chamada_publica_ifet.pdf>. Acesso em: 1 mai. 2015.

7. L_ Lei no 11.892, de 29 de dezembro de 2008. Disponível em: http://www.planalto.gov.br. Acesso em: 10 fev. 2015.

8. Decreto no 5.840, de 13 de julho de 2006. Disponível em: < http://www.planalto.gov.br/ccivil_03/_ato2004-2006/2006/decreto/D5840.htm>. Acesso em: 20 mai. 2015.

$9 . \quad$ Lei no 12.513, de 26 de outubro de 2011. Disponível em:< http://www.planalto.gov.br/ccivil_03/_ato2011-2014/2011/lei/l12513.htm>. Acesso em: 20 mai. 2015.

10. DEITOS, Roberto Antônio. Políticas Públicas e educação: aspectos teórico-ideológicos e socioeconômicos. Acta Scientiarum. Education, Maringá, v.32, n.2, p. 209-218, 2010. DOI: 10.4025/actascieduc.v32i2.11869.

11. FLEURY, S. Estado sem cidadãos: seguridade social na América Latina [online]. Rio de Janeiro: Editora FIOCRUZ, 1994. 252 p. ISBN 85-85676-06-X. Disponível em: http://books.scielo.org. Acesso em: 20 set. 2014.

12. HADDAD, Sérgio (org.) O Banco Mundial, OMC e FMI: o impacto nas políticas educacionais. São Paulo: Cortez, 2008.

13. LIMA, Fernanda Bartoly G. A formação de professores nos Institutos Federais de Educação, Ciência e Tecnologia: Um estudo da concepção política. Dissertação de Mestrado - UNB, 2012.

14. MÉSZÁROS, István. Educação para além do Capital. Tradução de Isa Tavares. São Paulo: Boitempo, 2007.

15. MINISTÉRIO DA EDUCAÇÃO. Portaria no 1.015, de 21 de julho de 2011. Disponível em: < http://www.mds.gov.br/brasilsemmiseria/legislacao-2/legislacao/arquivos/portariamulheres-mil-n-1015.pdf>. Acesso em 20 mai. 2015.

16.

Relatório Educação para todos no Brasil 2000-2015. MEC, 2014. Disponível em: < http://portal.mec.gov.br/index.php?option=com_content\&view=article\&id=20514: consultapublica-ao-relatorio-educacao-para-todos-no-brasil-2000-2015\&catid=454\&ltemid=164>. Acesso em: 20 mai. 2015.

17. OLIVEIRA, Francisco. Hegemonia às avessas. In: OLIVEIRA, Francisco; BRAGA, Ruy; e RIZEK, Cibele (orgs). Hegemonia às avessas: economia, política e cultura na era da servidão financeira. - São Paulo: Boitempo, 2010.

18. OTRANTO, Célia Regina. Criação e Implantação dos Institutos Federais de Educação, Ciência e Tecnologia - IFETs. Retta, vol. 1, no 1, p.98-108. Jan-jul 2010. Disponível em:http://www.ufrrj.br/SEER/index.php?journal=retta\&page=article\&op=view\&path\%5B\%5 $D=495 \&$ path\%5B\%5D=243. Acesso em: 19 set. 2014.

19. RODRIGUES, José. Os empresários e a educação superior. São Paulo-Campinas: Autores Associados, 2007.

20. VIEIRA, E. A. Democracia e política social. São Paulo: Cortez; Autores Associados, 1992. 